\title{
Homero frente a Hesíodo en el s. IV d. C.: a propósito de una cita de Hesíodo (Op. 412) en Himerio (Or. LXXIV, 2-3)
}

\author{
Virginia MuÑoz Llamosas \\ Universidad de Oviedo \\ munozvirginia@uniovi.es
}

Recibido: 9-10-2012

Aceptado: 20-12-2012

\begin{abstract}
RESUMEN

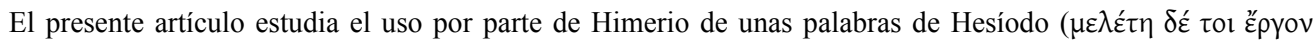
ó $\varphi \varepsilon ́ \lambda \lambda \varepsilon 1, O p$. 412) que son atribuidas por el orador a un «honorable poeta». La falta de atribución expresa podría deberse a que Himerio no conocía al autor de la cita o a una confusión con Homero. Para tratar de contestar a esta cuestión estudiamos, en primer lugar, la cita en sí y sus apariciones en el resto de la literatura griega; a continuación, el modo de citar de Himerio y los autores que maneja y, por último, la posibilidad de que se diese esa confusión entre Homero y Hesíodo, teniendo en cuenta la recepción en la antigüedad de cada uno de ellos.
\end{abstract}

Palabras clave: Himerio, Homero, Hesíodo, cita, recepción.

\begin{abstract}

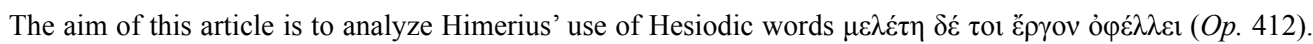
Himerius does not mention Hesiod, but says these words belong to a «distinguished poet». This lack of information about the author could be explained by Himerius' ignorance of the author of his quotation or by a confusion with Homer. To answer to this question we will examine first the quotation itself and its other occurrences in Greek Literature; then, how does Himerius quote other authors and which authors are quoted by him. Finally, we will explore the possibility of a confusion between Homer and Hesiod and their reception in antiquity.
\end{abstract}

Keywords: Himerius, Homer, Hesiod, quotation, reception.

El análisis de las citas empleadas por un autor tiene un gran interés intrínseco, en tanto que es un indicador del conocimiento que ese autor tenía sobre su pasado cultural, a lo que se suma la posibilidad de evaluar su trascendencia para la conservación de la literatura anterior. El presente trabajo forma parte del proyecto «La tradición literaria griega en los ss. III-IV d.C.: gramáticos, rétores y sofistas como fuentes de la literatura greco-latina» ${ }^{1}$, que estudia una selección de autores de los siglos III-IV d. C.

\footnotetext{
${ }^{1}$ Ref. (MICINN-12) FFI2011-30203-C02-01.
} 
con el objetivo de poder valorar, tanto individual como globalmente, su papel en la transmisión indirecta ${ }^{2}$ de la literatura greco-latina después de haber despojado, sistemáticamente y partiendo de los estudios más modernos sobre citación ${ }^{3}$, todas las citas, alusiones, imitaciones, etc. que hay en cada uno de ellos.

El discurso LXXIV de Himerio ${ }^{4}$ trata sobre la necesidad de practicar continuamente, ya que sólo a través del ejercicio constante se puede llegar a la perfección. Comienza con las siguientes palabras:

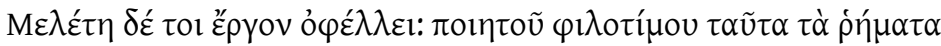

«La práctica ayuda al trabajo»: estas son las palabras de un honorable poeta.

La cita, que Himerio utiliza sin ningún tipo de expresión introductoria, se corresponde de manera literal con el segundo hemistiquio, a partir de la cesura pentemímera, del verso 412 de los Trabajos y días de Hesíodo. Himerio, como hemos visto, no identifica al autor, aunque sí dice que es un poeta y se pronuncia favorablemente sobre él

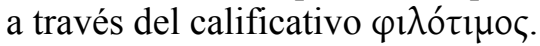

Ante esta situación, nos planteamos si Himerio conocía la autoría de la cita y, simplemente, no dio en este caso el nombre del poeta; si no citó expresamente a Hesíodo porque no sabía a qué poeta concreto pertenecían estas palabras; o si al atribuirlas al «honorable poeta» estaba pensando en Homero. Y para tratar de responder a esta cuestión nos fijaremos en tres puntos:

1. En primer lugar, en la cita en sí, rastreando si aparece o no en otros autores y, en caso de aparecer, si hay atribución expresa y si ésta es correcta.

2. En segundo lugar, observaremos los autores que son citados por Himerio, así como en el modo de citarlos: si sus citas son literales o no; si las introduce con alguna fórmula o si aparecen, como en nuestro pasaje, ex abrupto; si identifica al autor de la cita, etc.

3. En tercer lugar, exploraremos la posibilidad de que se diera esa confusión entre Homero y Hesíodo, teniendo en cuenta la recepción de ambos poetas, especialmente en autores contemporáneos de Himerio, que eran receptores de la misma tradición cultural.

Comenzando por el análisis de la cita en sí, la encontramos ligeramente alterada en la Ístmica sexta de Píndaro, versos 66-67, donde el poeta alaba el proceder de Lampón, que siguiendo el consejo de Hesíodo perpetúa una estirpe de campeones. Dice así:

${ }^{2}$ La importancia de esta tradición ha sido subrayada, entre otros, por Tosi (1988).

${ }^{3}$ Por ejemplo, Reyes (1993 y 1996), Fraser (1990) 383-395; Schiffrin (1987), Coulmas (ed.) (1986), Récanati (1999), Rosier (1999: 2). Referidos a las lenguas antiguas: Kroon (1995 y 1998), Garcea - Bazzanella (1999), Most (ed.) (1997).

${ }^{4}$ Puede verse información general sobre este autor en VVAA, Der Neue Pauly, 5, Stuttgart, 1998, s. v. Himerios, W. Smith (ed.), A Dictionary of Greek and Roman biography and mythology, Londres, 1848, s. v. Himerius, Kazhdan (1991), s. v. Himerios, Barnes (1987), o en la introducción a la traducción de Penella (2007). 


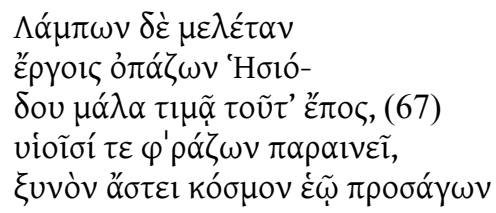

«Y Lampón, entretanto, poniendo todo el celo en su trabajo, honra el dicho de Hesíodo y lo cuenta a sus hijos y lo explica, dando parte a su patria de la gloria que alcanzan» (traducción Alsina)

Este prometedor comienzo podría hacernos pensar que las palabras de Hesíodo van a convertirse en una máxima transmitida de generación en generación. De hecho, estas palabras, cuya forma métrica se corresponde con uno de los esquemas denominados por Pellizer (1972) «metremas proverbiales» ${ }^{5}$, el metrema enoplio-paremiaco, parecen proceder de una tradición oral de poesía gnómica que, según se ha demostrado, es independiente a Homero ${ }^{6}$, y en opinión de Pellizer (1972, 27-28) representan una

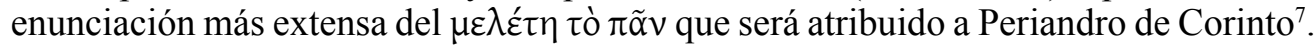
Pero la realidad es que ni las palabras de Hesíodo ni las atribuidas a Periandro aparecen con frecuencia en los textos griegos: tras este pasaje pindárico no reencontramos la cita hasta Himerio ${ }^{8}$, y después de Himerio sólo aparece en tres autores bizantinos: el primero de ellos, Nicetas Magistros ${ }^{9}$, fue un oficial de alto rango del siglo x que, acusado de tratar de deponer al emperador Romano Lecapeno, fue desterrado. Desde su destierro escribe unas Epistulae ex Hellesponto, y en la novena habla de quienes creen que la poesía es producto de una inspiración que tiene que ver con Hermes, las Musas o Apolo, mientras que él cree más bien en el trabajo continuo al que hace referencia

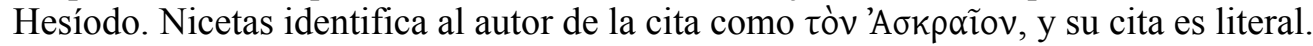

Tres siglos después, en el XIII, volvemos a encontrar la cita en la obra de Nicéforo Blemida, en un discurso que probablemente fue pronunciado en la coronación de Teo-

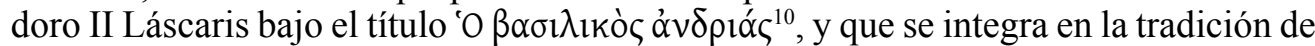
obras llamadas «Espejos del príncipe». Estas obras recogían directrices morales y de

${ }^{5}$ V. también Ercolani (2010).

${ }^{6}$ Remitimos a los trabajos que más contribuyeron a demostrar la existencia de una tradición oral independiente a la seguida por Homero: Hoekstra (1957), Notopoulos (1960), de Hoz (1974), Fernández Delgado (1978).

${ }^{7}$ D. L. I. 99. 5. Según la Antología griega (Anthologia Graecae Appendix, 48. 9), las palabras de

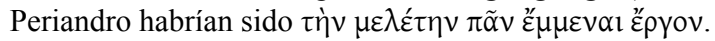

${ }^{8}$ Hay que notar, no obstante, que a pesar de que estas palabras no se convierten en una máxima proverbial, la idea que encierran sí será fundamental en toda la educación antigua, que se basa en la práctica continua y la emulatio de los grandes autores del pasado. Una imagen frecuente que recoge esta idea de la necesidad de una práctica constante es la del entrenamiento gimnástico, como indica el

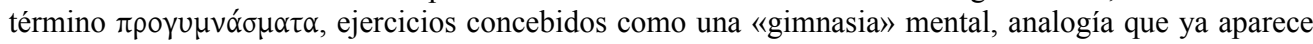
recogida en un escolio a Aftonio (Waltz, Rhetores Graeci, 2, 566). V. Cribiore (2001) y Webb (2001). Los $\pi \rho \circ \gamma \cup \mu v \alpha ́ \sigma \mu \alpha \tau \alpha$ que han llegado hasta nosotros han sido recopilados por Kennedy (2003).

${ }_{9}^{9}$ Sobre este autor puede verse Hevia Ballina (1975) o también Kazhdan (1991) s. v. Niketas Magistros.

${ }^{10}$ Véase Soto Ayala (2010) Kazhdan (1991) s. v. Blemmydes, Nikephoros. 
gobierno con el objetivo de formar a un buen soberano cristiano, y tienen sus raíces ${ }^{11}$ en la tradición retórica de Isócrates. Pues bien, en el capítulo vIII, habla del ejército y de cómo debe volcarse en el entrenamiento, y recuerda una ocasión en que el ejército romano fue rodeado por germanos y, contra todo pronóstico, logró romper el cerco y terminar rodeando él al enemigo, debido a su entrenamiento anterior. Nicéforo utiliza literalmente las palabras de Hesíodo, pero no identifica al autor de la cita.

Poco después, otro erudito bizantino, Teodoro Metoquites ${ }^{12}$, en una obra también de contenido didáctico titulada 'HӨıkò nuevo literalmente. Dado el contenido de la obra, la pertinencia de nuestra cita está asegurada, pero no así si Teodoro sabía quién era su autor, ya que utiliza la expresión

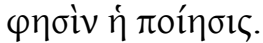

Las otras ocurrencias de estas palabras de Hesíodo están en los escolios y comentarios de las obras de Hesíodo y Píndaro. Los escolios a Hesíodo explican que $\mu \varepsilon \lambda \varepsilon \dot{\varepsilon} \tau \eta$

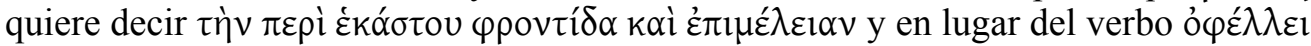
aparecen los verbos $\sigma \cup v \alpha u ́ \xi \varepsilon l$ y $\alpha u ́ \xi \varepsilon l$. En este punto hemos de decir que la búsqueda - mediante el $T L G$ - de la cita hesiódica cambiando alguno de sus elementos por los términos que aparecen en los escolios no ofrece ningún resultado.

Mayor interés tienen los escolios de Píndaro, que mencionan el verso en dos ocasiones, la primera de ellas a propósito de Nemea $6.54^{13}$, para explicar la forma $\mu \varepsilon \lambda \varepsilon ́ \tau \alpha v$. Curiosamente, el autor de la anotación se equivoca y atribuye la cita a Homero. En el segundo escolio en que aparece, correspondiente a la Ístmica sexta, donde el propio Píndaro cita a Hesíodo, no hay, naturalmente, error en la atribución. El error que comete el autor del escolio a la Nemea en la atribución de la cita, al suponer que se trata de una cita de Homero, unido a que Himerio afirma que se trata de las palabras de un

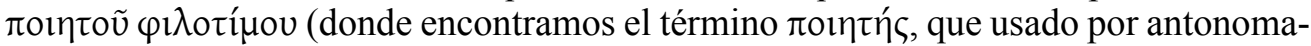
sia se adapta más a Homero que a Hesíodo), hacen pensar a Cuffari (1983: 46-47), en su trabajo sobre las citas poéticas de Himerio, que nos hallamos ante una expresión que, sacada de su contexto hesiódico, ha acabado por ser atribuida a Homero. Antes de apoyar o rechazar esta idea, creemos conveniente examinar los otros dos aspectos que mencionamos al principio.

El segundo punto tenía que ver con los autores citados por Himerio. El trabajo de Cuffari sobre sus citas poéticas comprende un total de 54 referencias, que, atendiendo a la literalidad de la cita, se pueden clasificar en citas literales, paráfrasis y citas «compendio». Desde el punto de vista del autor citado, se pueden clasificar en citas con mención expresa del autor, citas ocultas y citas anónimas. El autor más citado por Himerio es, con amplia diferencia, Homero, que aparece 26 veces, lo que supone un total de $48,1 \%$ de las citas poéticas de Himerio. El segundo más citado es Safo, con 6 apariciones $(11,11 \%)$. El tercer puesto, con 4 ocurrencias $(7,4 \%$ del total en cada caso), es compartido por Anacreonte, Simónides y las citas anónimas de autores dramáticos. El cuarto lugar, con tres citas cada uno (5,55\% del total en cada caso), lo

\footnotetext{
${ }^{11}$ Como ha mostrado Soto Ayala (2011 y 2009).

${ }^{12}$ Sobre este autor, $v$. Beck (1952), Ševčenko (1962) o De Vries-Van der Velden (1987), así como la información general ofrecida por Kazhdan (1991) s. v. Metochites, Theodore.

${ }^{13}$ Schol. ad Pind. Nem.VI 91b.
} 
ocupan Píndaro y Hesíodo. En quinto lugar, con una cita cada uno (1,85\% del total en cada caso) tenemos a Alceo, Posidipo, Menandro y las citas anónimas de la lírica.

Respecto al modo de citar, esto es, si se identifica o no al autor de la cita, como podemos ver, de las 26 veces que Himerio cita a Homero, en 21 ocasiones lo nombra expresamente, mientras que en 5 permanece oculto; Safo es identificada siempre; Anacreonte, en la mitad de sus 4 citas; Simónides, siempre, al igual que Píndaro, mientras que Himerio no hace mención expresa de Hesíodo nunca. Finalmente tenemos a Alceo, que sí es identificado, y a Posidipo y Menandro, que no lo son. De las 54 citas totales, en $37(68,5 \%)$ hay mención expresa del autor citado, mientras que en 17 $(31,48 \%)$ no la hay. De estas $17,5(9,25 \%)$ son citas anónimas, siendo $12(22,22 \%)$ las citas realmente ocultas. El caso que nos ocupa, por otra parte, es el único en el que una cita inicia ex abrupto un discurso.

La tercera cuestión que consideramos que debe plantearse para poder determinar con más seguridad si Himerio se equivocaba en la atribución de la cita es la posibilidad de que hubiera una confusión entre Homero y Hesíodo, y el modo en que estos dos poetas son citados en la época de Himerio. Esto nos lleva a hablar de su papel en el mundo griego, y de cómo fueron utilizados por los autores posteriores a ellos. Es bien sabido que Homero y Hesíodo han ejercido una gran influencia en la literatura posterior, y que, en el caso de Homero, nos encontramos ante el «educador» de Grecia, la «Biblia» de los griegos. ¿Sucede lo mismo con Hesíodo? Lo primero que tenemos que tener en cuenta al estudiar la recepción de Homero y Hesíodo en la Antigüedad es que, por un lado, está la realidad de estos poetas y sus obras; por otro, el modo en que los antiguos los imaginaron y utilizaron ${ }^{14} ; \mathrm{y}$, finalmente, el modo en que los concibe la crítica moderna, que en ocasiones distorsiona la visión de los antiguos. Así, por ejemplo, actualmente se da más importancia a la Teogonía que a los Trabajos, y todas las ediciones de Hesíodo comienzan con este poema, pero en la Antigüedad, a juzgar por el número de citas de una y otra obra, siempre superior para Trabajos ${ }^{15}$ - excepto en época helenística, cuando son más las citas de Teogonía - y por el número de manuscritos, era justo al revés, e incluso existía una tradición beocia, recogida por Pausanias $^{16}$, que afirmaba que los Trabajos era la única obra de Hesíodo. De hecho, es de los Trabajos y no de la Teogonía de donde Hesíodo extrae sus pasajes más representativos para enfrentarse a Homero en el Certamen, mientras que éste, por su parte, selecciona unos versos de la Ilíada que, lejos de ser considerados por la crítica moderna lo más representativo de su poesía, han sido incluso considerados espurios ${ }^{17}$.

En una reciente tesis doctoral leída en la Universidad de Leiden con el título $\mathrm{He}$ siod: The other poet, Koning (2010) plantea un acercamiento a la figura de Hesíodo,

${ }^{14}$ Entre los trabajos recientes que pretenden reconstruir la idea que de Homero tenían los antiguos destacan Graziosi (2002: 164-200), que en el capítulo «Homer's relationship to other poets», trata sobre la relación de Homero con otros poetas, entre los que se encuentra, naturalmente, Hesíodo; Rutherford (1996: 20-24; Hunter (2004); Zeitlin (2001); Lamberton (1996); Graziosi (2008).

${ }^{15}$ Por ejemplo, los oradores áticos del siglo IV no citan jamás la Teogonía y sí los Trabajos, como puede verse en Perlman (1964: 163).

${ }^{16}$ Pausanias 9.31.4.

${ }^{17}$ Sobre el enfrentamiento entre Homero y Hesíodo en el Certamen, véase Graziosi (2002: 168ss.) o Rosen (1996). 
al modo en que los griegos le imaginaron, leyeron y citaron, y cómo Hesíodo formaba parte de su memoria colectiva. Para ello, estudia más de 1200 referencias al poeta desde los comienzos de la literatura griega hasta el siglo III d. C. que se clasifican en tres grupos: Un primer grupo son las referencias en las que Hesíodo es citado junto a Homero (31\% de las referencias manejadas por Koning); en el segundo, Hesíodo aparece citado en solitario (60\%); y en el tercero, Hesíodo se cita como opuesto a Homero (sólo el 1\% de las referencias). El autor alerta ante la existencia, en la crítica moderna, de un muy frecuente «homerocentrismo» que se traduce en una atención mucho mayor a Homero que a Hesíodo, y hace observar cómo, en los casos más graves, Hesíodo, que a lo largo de los siglos fue palideciendo ante un Homero que se alzaba como el verdadero icono cultural, es completamente absorbido por éste, de manera que pueden atribuirse a Homero palabras y pensamientos que eran de Hesíodo, distorsionando así la realidad ${ }^{18}$. Pero no es la crítica moderna y sus posibles confusiones lo que más nos interesa, sino si esto mismo sucedió o no en la Antigüedad.

El trabajo de Koning revela tres imágenes diferentes y complementarias de Hesíodo; la primera es la que aparece cuando ambos poetas se citan asociados, erigiéndose en autoridad en temas éticos, religiosos ${ }^{19} \mathrm{e}$ incluso legales. De este modo, tanto Homero como Hesíodo forman parte del curriculum en las escuelas y están en la base de la paideia griega, punto confirmado por los papiros escolares de época helenística y romana $^{20}$. Es común citarlos para referirse a la épica en general, con lo que estos dos autores estarían funcionando como arquetipos del género épico, y también citarlos como arquetipo de la poesía en general, poseedores de un saber verdaderamente enciclopédico ${ }^{21}$.

En cambio, los pasajes en los que Hesíodo aparece solo, sin combinarse con Homero, revelan un Hesíodo diferente, considerado autoridad en cuatro temas centrales: demonología y vida después de la muerte, justicia en el seno de la ciudad, la relación entre el hombre y la ciudad, y la moderación. Incluso se observa que, cuando Hesíodo es citado en solitario, se le alaba por temas por los que era criticado cuando se le citaba junto a Homero, y no aparece a primera vista esa imagen típica del poeta vinculado a la paz, el pueblo llano y la agricultura, a pesar de que esto está relacionado con los

${ }^{18}$ Como muestra de ese «homerocentrismo» y su alteración de la visión que autores antiguos tenían de sus predecesores, véase el ejemplo que pone Koning (2010: 14, n. 33): «In more extreme cases, Hesiod is wholly absorbed by Homer, losing all individuality; thus Mehmel claims that Heraclitus dislikes Homer for his polymathy, although Heraclitus in fact attributes that quality to Hesiod (Mehmel, 1954: 21). In such cases, our disproportional focus on Homer distorts the ancient picture».

${ }^{19}$ Todos conocemos el famoso pasaje de Heródoto (2. 53) en el que hace a ambos poetas creadores de una teogonía para los griegos y responsables de haber dado a cada dios sus atribuciones, epítetos, etc.

${ }^{20} \mathrm{~V}$. Morgan (1998), Cribiore (2001: 194-200) o Wissmann (2010), además de los testimonios de autores antiguos como Heráclito (DK B57), Platón (R. 377c), Esquines (In Ctes. 135), Libanio (Or. 16, 46) o Plutarco (Mor. 28b).

${ }^{21}$ Ya Havelock (1994: 71-92 y 101-155) hablaba de la «enciclopedia» homérica, algo que en buena parte puede extenderse a Hesíodo, pues ambos son considerados por los griegos los pilares de la educación, como podemos ver en la lucha que Platón entablará con los poetas al tratar de despojarles del lugar que ocupaban en la paideia griega. Sobre las distintas áreas de conocimiento en las que se consideraba autoridad a Hesíodo, v. Koning (2010: 93, n. 16); Máximo de Tiro (26.1ss.) recoge los distintos ámbitos del saber homérico. 
temas por los que más se le cita (comportamiento del hombre en la ciudad, consejos sobre la arrogancia, etc.). Un punto muy llamativo es que cuando Hesíodo es considerado en solitario se le ve como precedente de la filosofía, no sólo por haber tratado acerca de la cosmogonía, sino por el modo en que lo hizo, mientras que Homero nunca será considerado uno de los filósofos naturales.

Por último, en las citas en las que Hesíodo aparece enfrentado a Homero (y aquí se incluye toda la tradición relativa a la competición entre ambos en el Certamen) se subraya el contraste entre tres aspectos de su poesía, el contenido (guerra frente a agricultura), la orientación ético-política del autor (rey frente a pueblo) y el efecto de sus poemas sobre el público (emoción frente a razón). Al destacar los rasgos que los oponen, vemos que se produce un curioso fenómeno, y es que, mientras que Hesíodo, relacionado con la paz y la vida del campo, no puede ser considerado «poeta de la guerra», a pesar de que en su obra hay guerra y lucha (pensemos, por ejemplo, en la Titanomaquia), Homero a menudo es considerado tan universal que sí puede «invadir» áreas tradicionalmente reconocidas como hesiódicas. Esta tendencia irá en aumento desde la época clásica en adelante ${ }^{22}$, incluso en época helenística, cuando Hesíodo aparezca como modelo de un nuevo tipo de poesía y se revalorice ${ }^{23}$, pero siempre a partir de los rasgos que le oponían a Homero, y sin que ello suponga que éste pase a un segundo plano. En otras palabras, a partir de la época helenística vemos que Homero puede en ocasiones ser «hesiódico» en sus temas y estilo, pero en cambio Hesíodo no puede ser «homérico». Y de ahí que en la época de la segunda sofística Homero sea el único icono cultural y artístico, absorbiendo temas tradicionalmente hesiódicos, lo que aumentaría la posibilidad de una confusión, siempre a favor de Homero, en la atribución de una cita ${ }^{24}$. En este punto no está de más recordar, como hace Graziosi (2008), que el texto de Homero que manejamos se debe principalmente al trabajo de los alejandrinos, y que puede variar respecto al que se manejaba anteriormente. Efectivamente, West ${ }^{25}$ apunta que la mayoría de las citas homéricas de autores antiguos se remontan a la recensión ática del texto realizada en el siglo vI a.C., recensión que no habría evitado las variantes que encontramos, por ejemplo, en las citas homéricas de Platón y Aristóteles, y que siguen testimoniándose en los primeros papiros con texto homérico, de los siglos III-II a.C. Sí habrá un cambio sustancial a partir del 150 a. C., probablemente debido a la labor de Aristarco, de forma que los papiros más tardíos no difieren mucho de la tradición manuscrita. Esto hace que, como mínimo, nos planteemos la posibilidad de que cuando una cita se atribuye a Homero, pero no coincida con el texto que ahora manejamos como homérico, la causa pueda estar no sólo en esa

${ }^{22}$ Por ejemplo, Macía Aparicio (2000) ya indica que «Aristófanes considera obra de Homero prácticamente todos los poemas épicos».

${ }^{23}$ El carácter didáctico que se le atribuye a la poesía de Hesíodo contribuye a «clasificarlo» desde el punto de vista del género, y así aparecerá en los manuales griegos de retórica y también entre los autores romanos ligado a subgéneros como la máxima o la fábula. La obra de Hesíodo que más influye en los autores romanos es, de nuevo, Trabajos.

${ }^{24}$ En realidad esto ya sucedía en época clásica, como señalan Perlman (1964: 165 y nota 59 para las referencias a los pasajes) o Graziosi (2002: 164ss.), que comenta diferentes pasajes en los que paulatinamente se alejan de la figura de Homero poemas épicos de otros autores.

${ }^{25}$ West (1988). 
«expansión» de Homero, sino, quizá, en que el texto de Homero era más amplio que el aceptado actualmente.

Veamos ahora la proporción entre las citas de Homero y las de Hesíodo en diferentes autores herederos de la misma tradición cultural que Himerio. Los datos hablan de una incuestionable superioridad de Homero, y así, por ejemplo, Juliano cita 171 veces a Homero frente a 11 citas de Hesíodo, lo que nos da una proporción de 15,5:1, similar a la de $\operatorname{Ateneo~}^{26}$ (348 citas de Homero y 22 de Hesíodo, proporción 16,13:1), Dionisio de Halicarnaso ${ }^{27}$ (37 citas de Homero, 3 de Hesíodo, proporción 12,33:1), Quintiliano (41 citas de Homero y 3 de Hesíodo, proporción 13,66:1), o Aftonio (11 citas de Homero y sólo 1 de Hesíodo, proporción 11:1). La superioridad de Homero es menos acusada en otros autores como Plutarco 28 (889 citas de Homero y 207 de Hesíodo, proporción 4,29:1), Basilio de Cesarea (23 citas de Homero y 4 de Hesíodo, proporción 5,75:1) o Hermógenes (9 citas de Homero y 2 de Hesíodo, proporción 4,5:1). Himerio estaría en un lugar intermedio, ya que presenta 26 citas de Homero y 3 de Hesíodo, con una proporción 8,6:1. Más allá de los datos puramente cuantitativos, hay que observar el modo en que ambos autores son citados, y aquí hay una coincidencia llamativa entre Juliano e Himerio. Efectivamente, Juliano demuestra conocer perfectamente a Homero, y sus citas, casi siempre con mención expresa del autor, indican que manejaba directamente el texto homérico, mientras que las citas hesiódicas son de segunda mano y pertenecen básicamente a los Trabajos, que, como ya hemos dicho, es mucho más citada en la Antigüedad que la Teogonía. Pero aún hay otro dato interesante en Juliano, y es que comete un error en la atribución de una de sus $\operatorname{citas}^{29}$, que considera de Homero, cuando en realidad pertenece a Hesíodo ${ }^{30}$. Esto probaría ${ }^{31}$ que, en general, en la cultura de Juliano las fórmulas épicas se relacionan con Homero y que, especialmente, si la fórmula pierde el vínculo con su autor, se le atribuye de forma automática.

El modo en que Himerio citaba a Homero (21 citas con mención expresa del autor y sólo 5 ocultas) indica que, de manera similar a Juliano, tenía un buen conocimiento de la Ilíada y la Odisea, mientras que las citas de Hesíodo, todas ellas ocultas, parecen señalar un conocimiento más superficial y quizá de segunda mano. A ello aún podemos sumar el que normalmente la designación ó tooñńs se refiere a Homero, y así sucede en las dos ocasiones en que lo emplea Himerio ${ }^{32}$, y no a Hesíodo, hecho que está en perfecta consonancia con la «expansión» experimentada, a costa de Hesíodo, por la figura de Homero. Y esto no es en modo alguno un hecho aislado, como podemos observar a partir de otra cita de Himerio (45.7), donde menciona el adjetivo $\varphi v \lambda \lambda$ oxóov, que se aplica a un mes, y que, según dice, él ha escuchado a los «hijos

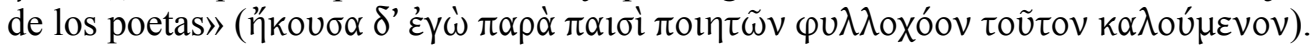

${ }^{26}$ Datos que agradecemos a la Dra. Rodríguez-Noriega Guillén, autora de la traducción española de Ateneo.

${ }^{27}$ Los datos referidos a Dionisio de Halicarnaso, Quintiliano, Plutarco, Hermógenes y Aftonio han sido tomados de la tabla ofrecida por Morgan (1998: 318).

${ }^{28}$ Sobre las citas en Plutarco contamos también con el trabajo de Helmbold - O’Neil (1959).

${ }^{29}$ En Misop. 17, 347c.

${ }^{30} \mathrm{Op} .66$.

${ }^{31}$ Según Bouffartigue (1992).

${ }^{32}$ En Or. 48.14 y 65.7. 
Este adjetivo aparece por primera vez en un fragmento de Hesíodo ${ }^{33}$ y se testimonia también en Plutarco ${ }^{34}$, Calímaco ${ }^{35}$, Apolonio Rodio ${ }^{36}$ o Nonno ${ }^{37}$, y lo llamativo es que Eustacio $^{38}$ se lo atribuye a Homero, mientras que Pólux ${ }^{39}$ lo relaciona con Hesíodo.

Aunque no es posible alcanzar la seguridad absoluta, creemos que los datos expuestos hacen bastante probable la equivocación de Himerio, y que, en cualquier caso, indican que un estudio detallado de las citas de los diferentes autores tiene mucho que aportar a nuestro conocimiento de la literatura antigua, la recepción de los diversos autores a través de los siglos, y la propia cultura literaria de los escritores tardíos.

\section{BIBLIOGRAFÍA}

BARNes, Timothy David (1987), «Himerius and the fourth century»,CPh 82.3: 206-225.

BECK, Hans-Georg (1952), Theodoros Metochites. Die Krise des Byzantinischen Weltbildes im 14 Jahrhundert, Munich.

Bouffartigue, Jean (1992) L'empereur Julien et la culture de son temps, Paris.

Coulmas, Florian (ed.) (1986), Direct and Indirect Speech, Berlín-Nueva York-Amsterdam.

CRIBIORE, Raffaella (2001), Gymnastics of the mind. Greek education in Hellenistic and Roman Egypt, Princeton.

CUffarI, Giuseppa (1983), I riferimenti poetici di Imerio, Palermo.

DE Hoz, Javier (1974); «Poesía oral independiente de Homero en Hesíodo y los Himnos homéricos», Emerita 32: 283-298.

De VRIES-VAn DeR Velden, Eva (1983), Theodore Metochite: une reevaluation, Amsterdam, 1987.

ErColani, Andrea (2010), «Enunciati sentenziosi nelle Opere e Giorni di Esiodo», Lelli, Ema-

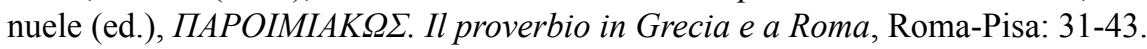

Fernández Delgado, Jose Antonio (1978), «Poesía oral gnómica en los “Trabajos y los días": una muestra de su dicción formular», Emerita 46.1: 141-171.

FrASER, Bruce (1990), «An approach to discourse markers», Journal of Pragmatics 14: 383-395.

GARCEA, Alessandro - BAZZANella, Carla (1999) «Textual links and the functions of discourse particles in Aulus Gellius's "Noctes Atticae"), Lingua e stile 34: 403-430.

Graziosi, Barbara (2002), Inventing Homer. The early reception of epic, Cambridge.

Graziosi, Barbara (2008), «The ancient reception of Homer» en Hardwick, Lorna - Stray, Christopher (eds.), A companion to classical receptions, Oxford: 26-37.

Havelock, Erick A. (1994), Prefacio a Platón, Madrid, 1994 (Cambridge, 1963).

Helmbold, William Clark - O’Neit, Edward N. (1959), Plutarch's quotations, Baltimore.

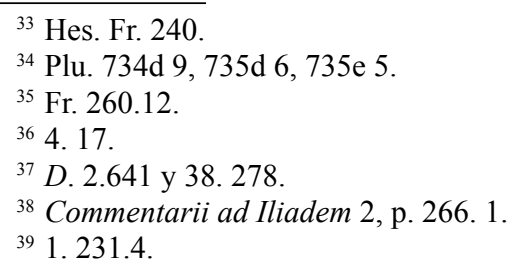


Hevia Ballina, Agustín (1975), «Perfil humano-religioso y humanístico-literario de Nicetas Magistro», Studium Ovetense 3: 7-58.

Hoekstra, Arie (1957), «Hésiode et la tradition orale. Contribution à l'étude du style formulaire», Mnemosyne 10: 193-225.

HunTER, Richard (2004), «Homer and Greek literature» en Fowler, Robert (ed.), The Cambridge companion to Homer, Cambridge: 235-253.

KazHDAn, Alexander P. (ed.) (1991), The Oxford Dictionary of Byzantium, New York.

Kennedy, George Alexander (2003), Progymnasmata: Greek Textbooks of Prose Composition and Rhetoric, Atlanta.

Koning, Hugo (2010) Hesiod. The other poet. The ancient reception of Hesiod, Leiden.

Kroon, Caroline (1995), Discourse particles in Latin. A study of nam, enim, autem, vero and at, Amsterdam.

Kroon, Caroline (1998), «A framework for the description of Latin discourse markers», Journal of Pragmatics 30: 205-223.

Lamberton, Robert (1996) «Homer in Antiquity» en Morris, Ian - Powell, Barry (eds.), A new companion to Homer, Leiden: 33-54.

Macía ApARICIO, Luis Miguel (2000), «Parodias de situaciones y versos homéricos en Aristófanes», Minerva, LVIII 2: 211-241.

Morgan, Teresa (1998), Literate education in the Hellenistic and Roman worlds, Cambridge. Most, Glenn W. (ed.) (1997), Collecting Fragments- Fragmente sammeln, Gotinga.

Notopoulos, James A. (1960), «Homer, Hesiod and the Achaean Heritage of Oral Poetry", Hesperia 29: 177-197.

Pellizer, Ezio (1972), «Metremi proverbiali nelle “Opere e giorni” di Esiodo» QUCC 13: 24-37.

Penella, Robert J. (2007), Man and the Word. The Orations of Himerius. Berkeley: University of California Press.

RÉCANATI, François (1999), Oratio obliqua, oratio recta. The Semantics of Representation, Paris.

ReYes, Graciela (1993), Los procedimientos de cita: estilo directo y estilo indirecto, Madrid.

REYes, Graciela (1996), Los procedimientos de cita: citas encubiertas y ecos, Madrid.

Rodríquez-Noriega Guillén, Lucía (1998-), Ateneo de Náucratis. Banquete de los eruditos, Madrid.

Rosen, Ralph M. (1996), «Homer and Hesiod» en Morris, Ian - Powell, Barry (eds.), A new companion to Homer, Leiden: 463-488.

Rosier, Laurence (1999), Le discours rapporté. Histoire, théories, pratiques, París.

Rutherford, Richard (1996), «Reception, ancient and modern», Homer, Oxford: 20-24.

S. Perlman (1964), «Quotations from poetry in Attic orators of the fourth century b. C.», $A J P h$ 85.2: $155-172$.

SchifFrin, Deborah (1987), Discourse markers, Cambridge.

ŠEVČENKO, Ihor. (1962), La vie intellectuelle et politique à Byzance sous les premiers Paléologues: Études sur la polémique entre Théodore Métochite et Nicéphore Choumnos. Corpus Bruxellense Historiae Byzantinae. Subsidia 3, Bruselas.

Smith, William (ed.) (1848), A Dictionary of Greek and Roman biography and mythology, London.

Soto Ayala, Roberto Andrés (2009), Los «Espejos de Príncipe» en el mundo bizantino como continuidad de la tradición retórico-política isocrática, Granada. 
Soto Ayala, Roberto Andrés (2010), «Nicéforo Blemida y la estatua del soberano: 'O $\beta \alpha \sigma \imath \lambda ı$ kò

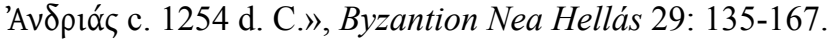

Soto Ayala, Roberto Andrés (2011), «Isócrates y los Espejos de Príncipe bizantinos», Byzantion Nea Hellás 30: 125-141.

Tosi, Renzo (1988), Studi sulla tradizione indiretta dei classici greci, Bolonia.

VVAA, Der Neue Pauly, 5, Stuttgart, 1998

WeBB, Ruth (2001), «The progymnasmata as practice», en Too, Yun Lee (ed.), Education in Greek and Roman Antiquity, Leiden: 289-316.

WEST, Stephanie (1988), «The transmission of the text» en Heubeck, Alfred - West, StephanieHainsworth, John Bryan, A Commentary on Homer's Odyssey, Oxford: 33-48.

Wissmann, Jessica (2010), «Education» en Clauss, James J. - Cuypers, Martine (eds.), A companion to hellenistic literature: $62-77$.

Zeitlin, Froma I. (2001), «Visions and revisions of Homer» en Goldhill, Simon (ed.), Being Greek under Rome. Cultural Identity, the Second Sophistic and the Development of Empire, Cambridge: 195-266. 